DR. CHIAO-LING LO (Orcid ID : 0000-0002-4781-3979)

Article type $\quad$ : Original Research Article

\title{
CIS-ACTING ALLELE SPECIFIC EXPRESSION (ASE) DIFFERENCES INDUCED BY ALCOHOL AND IMPACTED BY SEX AS WELL AS PARENTAL GENOTYPE OF
}

\section{ORIGIN}

\begin{abstract}
Chiao-Ling Lo ${ }^{1}$, Lawrence Lumeng ${ }^{2}$, Richard L. Bell ${ }^{2,3,5}$, Tiebing Liang ${ }^{2,4}$,
\end{abstract}
Amy C. Lossie $2,6,7$, Williams M. Muir²,6, Feng C. Zhou ${ }^{1,2,5}$

${ }^{1}$ Department of Anatomy \& Cell Biology, ${ }^{2}$ Indiana Alcohol Research Center,

${ }^{3}$ Department of Psychiatry, ${ }^{4}$ Department of Gastroenterology, ${ }^{5}$ Stark Neuroscience Research Institute, Indiana University School of Medicine, Indianapolis, IN, 46202, USA.

${ }^{6}$ Department of Animal Sciences, Purdue University, West Lafayette, IN, 47907, USA

${ }^{7}$ Current address: Division of Neuroscience and Behavior, Genetics, Epigenetics and Developmental Neuroscience Branch, National Institutes of Health, Bethesda, MD 20892, USA

This is the author's manuscript of the article published in final edited form as:

Lo, C.-L., Lumeng, L., Bell, R. L., Liang, T., Lossie, A. C., Muir, W. M., \& Zhou, F. C. (2018). Cis-acting allele specific expression (ASE) differences induced by alcohol and impacted by sex as well as parental genotype of origin. Alcoholism: Clinical and Experimental Research, 0(ja). https://doi.org/10.1111/acer.13776 
${ }^{*}$ Corresponding author

Feng C. Zhou, Ph.D.

Indiana University School of Medicine

Department of Anatomy and Cell Biology

1044 W. Walnut St. Rm 039

Indianapolis, IN 46202

Fax: +1-317-278-2040

Tel: +1-317-274-7359

Email: imce100@iu.edu

\section{ABSTRACT}

Background: Alcohol use disorders (AUDs) are influenced by complex interactions between the genetics of the individual and their environment. We have previously identified hundreds of polygenic genetic variants between the selectively bred high and low alcohol drinking (HAD and LAD) rat lines. Here we report allele specific expression (ASE) differences, between the HAD2 and LAD2 rat lines.

Methods: The HAD2 and LAD2 rats which have been sequenced were reciprocally crossed to generate 10 litters of F1 progeny. For 5 of these litters, the sire was HAD2; and, for the other 5 litters, the sire was a LAD2. From these 10 litters, two males and two females were picked from each F1 litter ( $N=40$ total). The F1-pups were divided, with balancing for sex and direction of cross, into an alcohol (15\%) vs a water control group. Alcohol-drinking started in the middle of This article is protected by copyright. All rights reserved. 
adolescence ( PND 35) and lasted 9 weeks. At the end of these treatments, rats were euthanized, the nucleus accumbens was dissected, and RNA was processed for RNA-sequencing and ASE analyses.

Results: Analyses revealed that adolescent ethanol drinking, individual ethanol drinking levels, parentage, and sex-of-animal affected ASEs of about 300 genes. The identified genes included those associated with ethanol metabolism (e.g., Aldh2); neuromodulatory function [e.g., Cckbr, Slc6a7, and Slc1a1]; ion channel activity (e.g., Kcnc3); as well as other synaptic and epigenetic function.

\section{Conclusion:}

These data indicate that ethanol drinking differentially amplified paternal vs maternal allelic contribution to the transcriptome. We hypothesize that this was due, at least in part, to ethanol-induced changes in cis-regulation of polymorphisms previously identified between the HAD2 and LAD2 rat lines. This report highlights the complexity of gene-by-environment interactions mediating a genetic predisposition for, and/or the active development of, alcohol use disorders.

KEYWORD: Gene-environment interaction, Genomics, Alcohol use disorder, Gender effect, Direction of cross, RNAseq, Epigenetics.

This article is protected by copyright. All rights reserved. 


\section{INTRODUCTION}

The extensive search for genetic contributions to alcohol use disorders (AUDs) has not identified, as of yet, any single nucleotide polymorphism (SNP) that has greater than a small, albeit significant, association with AUDs. Moreover, there are still significant gaps in our knowledge of the association between a large number of genetic variants and ethanol-associated effects including AUDs. Deciphering the role of SNPs in their associated gene function remains problematic (i.e. identifying the minority of functional SNPs from the much larger number of insignificant ones is a difficult task). This is underscored by the fact that AUD-associated genetic variants in coding regions [e.g. ADH2 (Treutlein et al., 2009, van Beek et al., 2010), GABRB2 (Edenberg et al., 2004, Sander et al., 1999), Grm2 (Zhou et al., 2013)] are rare. Moreover, it appears that most complex disease-associated variants have been identified as noncoding SNPs mapping outside the coding regions of various genes (Lo et al., 2016, Zhang and Lupski, 2015, Ward and Kellis, 2012, Manolio et al., 2009).

In the present study, we examined a deeper layer of SNP function targeting Allelic Specific Expression (ASE). ASE analysis allows us to examine cis-acting regulatory elements for variations associated with genetic differences in a predisposition to develop AUDs. Variability in the ASE of human phenotypes highlights the complex polymorphic gene regulation required for the underlying development of complex traits or diseases (Palacios et al., 2009, Huang et al., 2017). It is now known that ASE differences are relatively common among non-imprinted autosomal genes, and these differences can be transmitted across generations (Yan et al., 2002, Cowles et al., 2002, Lo et al., 2003). Thus, ASE analysis provides a powerful tool to identify functional polymorphisms as well as gene-by-environment expression patterns associated with the development of AUDs (Moyerbrailean et al., 2016), which is the focus of the current study.

This article is protected by copyright. All rights reserved. 
Recently, the genomic signature between the High Alcohol Drinking (HAD1) and the Low Alcohol Drinking (LAD1) rat lines, which meet most of the criteria put forth for a valid animal model of alcoholism (Li and Lumeng, 1984, McBride and Li, 1998, McBride et al., 2014), has been identified. Furthermore, a genomic comparison of a duplicate selectively bred, from the same ancestors, line-pair (HAD2 vs LAD2) has also been performed to determine potential complications associated with genetic drift (c.f. (Lo et al., 2016). Once this random drift was corrected for, we identified signatures for 780 coding SNPs, associated with 262 genes, and 21,083 non-coding SNPs, associated with $~ 900$ genes that were common between these two replicate line-pairs. We continue to interrogate this database to determine what transcripts resulted from inherited SNPs and whether they contribute significantly to cis-regulation of AUD-associated genes.

In the present study, we performed an ASE analysis by sequencing the RNA (RNA-seq) of the F1 progeny from a reciprocal cross of the HAD2 and LAD2 rat lines, with and without access to ethanol starting during adolescence. We prioritized this research by focusing on the nucleus accumbens (NAc), a key structure in the mesocorticolimbic reward circuit (Olsen, 2011, Di Chiara and Imperato, 1988). To test the effect of alcohol drinking on ASE, both Alcohol Drinking (AD: Alcohol Drinking vs Water only groups) and Alcohol Drinking Level (ADL) served as two factors for these analyses. To assess the role of paternal and maternal effects reciprocal crosses (HAD2 male x LAD2 female and LAD2 male x HAD2 female) were used; and, to assess the role of sex differences, tissue from both male and female F1 progeny were analyzed.

Therefore, the current study evaluated how alcohol drinking, parental genetic contribution, and sex-of-the-subject influenced cis-acting regulation of genes identified as being in allelic imbalance. The data revealed a significant [False Discovery Rate (FDR) set at 0.05] number, of 
allelic imbalances, as indicated by ASE differences occurred for hundreds of genes as a result of Alcohol Drinking $(A D)$ as well as Alcohol Drinking Level $(A D L)$. Allelic imbalances were also associated with sex differences in alcohol drinking levels. From the present study's reciprocal cross, the data revealed a differential influence of parental genotype [i.e. (male HAD x female LAD) vs (female HAD x male LAD)] on patterns of ASE. Overall, the present study not only detected differences in a significant number of genes previously highlighted in genetic studies on AUDs, but also identified new genes with ASE differences associated with alcohol drinking behavior. Note for the present discussion, ASE is indicative of cis-acting regulatory processes affected by alcohol exposure/drinking.

\section{METHODS}

\section{Breeding and Selection of Paired-lines}

The HAD2 and LAD2 lines were developed from the N/NIH heterogeneous stock (HS) rat line [an inter-cross of 8 different inbred rat strains with varying levels of ethanol intake (Manolio et al., 2009)] through bi-directional selective breeding. This selective breeding used within family selection and rotational (across families) breeding procedures at Indiana University (Hansen and Spuhler, 1984, Bell et al., 2017, Bell et al., 2012, McBride et al., 2014, Murphy et al., 2002). During selection, the rats were given free-choice (i.e., concurrent) access to food, water and a $10 \%(\mathrm{v} / \mathrm{v})$ ethanol solution. The selection criteria for the HAD lines were consumption of at least $5.0 \mathrm{~g}$ of ethanol $/ \mathrm{kg}$ body weight/day, and an ethanol to water volume ratio of at least $2: 1$; while LAD rats were required to drink less than $1.5 \mathrm{~g} / \mathrm{kg} /$ day with an ethanol to water volume ratio of less than 0.5:1. Bi-directional selection for $A D L$ was repeated for 30 consecutive generations, followed by $30+$ generations of selection that were interspersed with relaxed selection when the parents were not tested for $A D L$. At the $60^{\text {th }}$ generation, the HAD2 and LAD 2 were crossed in

This article is protected by copyright. All rights reserved. 
both directions, HAD2 (sire) x LAD2 (dam) ( $n=5$ of each) and LAD2 (sire) x HAD2 (dam) ( $n=5$ of each), to generate 10 litters from the 61 st generation. These ten litters were designated as $\mathrm{F} 1$ progeny for the current ASE study.

At weaning (post-natal day 21), tissue from the parents (generation 60) were harvested for DNA-sequencing and genetic variant analyses, which produced a high resolution genomic profile of the genetic architecture associated with alcohol preference (Lo et al., 2016). Two males and two females from each $\mathrm{F} 1$ litter ( $\mathrm{N}=40$ total) were divided, with balancing for sex and direction of cross, into an alcohol drinking $(A D)$ group, with concurrent access to a bottle of $15 \%$ alcohol and a bottle of water, vs a water control group, with concurrent access to two water bottles. Drinking treatment (alcohol vs water) started mid-adolescence [ post-natal day (PND) 35]. The drinking lasted for 9 weeks and the drinking scores were recorded 5 days/week before brain tissue was harvested from these F1 progeny. The second bottle (either alcohol for the $A D$ group or water for the water control group) was removed four hours before the brains were harvested. The nucleus accumbens (NAc), a central structure of the mesocorticolimbic reward circuit, was microdissected using Paxinos and Watson's atlas (2006) with a $2 \mathrm{~mm}$ section generated from a coronal cut at Bregma +1.70 and a coronal cut at Bregma -0.26 using the lateral ventricle and the anterior commissure as landmarks. The RNA was then harvested for RNA-sequencing and ASE analyses. The ventral tegmental area (VTA) was also dissected for future studies. All rats, mentioned above, were euthanized by $\mathrm{CO}_{2}$ inhalation which was quickly followed by decapitation and the brains extracted. This animal research was approved by the Indiana University School of Medicine IACUC, under protocol \# 11085 MD/R.

This article is protected by copyright. All rights reserved. 


\section{RNA Isolation and Improvement}

The entire nucleus accumbens (NAc) and in additional a trial region ventral tegmental area (VTA) of the control and alcohol groups were microdissected under a Leitz inverted microscope, homogenized in $1 \mathrm{ml} \mathrm{TRIzol} \mathrm{reagent,} \mathrm{and} \mathrm{stored} \mathrm{at}-80^{\circ} \mathrm{C}$. Initially, the VTA was isolated from the samples and 200ul chloroform added was followed by centrifuging for phase separation. The aqueous layer was removed and the sample transferred to a new tube and mixed with $600 \mathrm{ul}$ of $70 \% \mathrm{EtOH}$. The mixture was loaded onto RNeasy spin columns supplied in the Qiagen RNeasy Micro kit (Qiagen, Germantown, MD) followed by an RNA buffer 1 (RW1) wash with the remaining steps following the manufacturer's protocol. Using this method, the sample variation was large and had unsatisfactory RNA yield and purity. Based on Nanodrop measurement, the total amount of RNA from the VTA ranged from 0 to $1.1 \mathrm{ug}$, and most of the samples had a shifted peak at $270 \mathrm{~nm}$ with low $260 / 230$ ratio, suggesting the presence of phenol contamination. Overall, these measures suggested that the concentration reading from Nanodrop did not represent the true amount of RNA. After further optimization, to avoid phenol contamination, NAc RNA was isolated using the Macherey-Nagel NucleoSpin RNA XS kit (Macherey-Nagel, Bethlehem, PA) following the manufacturer's instructions. The Trizol lysates were first thawed at $37^{\circ} \mathrm{C}$ for $2-3$ minutes to ensure salts were completely dissolved. RA3 wash buffer (600ul) and repeated wash steps were used to prevent TRIzol carryover. For samples that had TRIZol carryover, re-purification with a new spin column successfully eliminated TRIZol contamination. With these improvements, we were able to increase the yield of total RNA from NAc samples ranging from $963 \mathrm{ng}$ to $5.2 \mu \mathrm{g}$.

\section{RNAseq Library Preparation and Sequencing}

Approximately $100-300 \mathrm{ng}$ of total RNA was used for RNA-Seq library preparation following the Illumina TruSeq stranded mRNA sample preparation guide (illumina, San Diego, CA), by

This article is protected by copyright. All rights reserved. 
purifying the poly-A containing mRNA molecules using poly-T oligo-attached magnetic beads. Following purification, the mRNA was fragmented using divalent cations under elevated temperature. For 100bp paired-end sequencing, the target fragment size was 200-300bp of RNA and the average for the library was about 350-450bp after library preparation. Reverse transcription of the mRNA was performed using reverse transcriptase and random primers, followed by second strand cDNA synthesis using DNA Polymerase I and RNase $\mathrm{H}$. In the stranded RNA-seq procedure, strand specificity was achieved by replacing dTTP with dUTP in the Second-Strand Marking Mix (SMM). The incorporation of dUTP in the second strand synthesis effectively quenches the second strand during amplification, since the polymerase used in the assay cannot incorporate further nucleotides beyond dUTP. Further specificity was achieved by the addition of Actinomycin D to the First Strand Master Mix Act D (FSA). Actinomycin prevents spurious DNA dependent synthesis during first strand synthesis, while allowing RNA-dependent synthesis. These cDNA fragments then went through an end-repair process, with the addition of a single ' $A$ ' base followed by ligation of the adapters. The products were then purified and enriched with PCR to create the final RNA-Seq library. The libraries were then subjected to quantification, pooled for cBot amplification, and subsequent sequencing on an Illumina HiSeq 2000 platform (illumina, San Diego, CA). The pooling scheme was an average of 2 samples per lane. After the sequencing run, demultiplexing with CASAVA was employed to generate the fastq file for each sample and removal of the adapter sequences. On average, the coverage was 17.6 GB for all samples or approximately 100 million paired-end reads.

\section{Sequence Read Mapping and Genotype Calling}

Sequence reads were mapped using the RNA-Seq analysis tool CLC Genomics Workbench V9.5.2. The tool maps reads to transcripts of Rattus Norvegicus using version 6.0.83.gtf

This article is protected by copyright. All rights reserved. 
annotation files (Ensembl 2016). Mapping errors were minimized by setting the cost of insertions and deletions to the maximum value allowed and requiring $90 \%$ of the read (including both ends of the pair) to map uniquely to the transcript with $90 \%$ similarity. Reads that mapped to more than one transcript were ignored. The raw sequencing data is available at NCBI SRA database (SRA accession: SRP126749).

All differences from the reference genome, including putative SNPs, insertions, and deletions were then called using the basic variant detection tool of CLC. For calling SNPs, a minimum allele frequency of $5 \%$ was required. The presence of SNPs, as opposed to sequencing or mapping errors, was confirmed by across sample verification, i.e. the same SNP called in at least 3 independent samples. Random errors rarely repeat themselves. Individual genotypes were called as follows. If the individual sample coverage was less than 3 , a missing value was assigned. If the coverage was greater than 2 and the base was the same as the reference, it was classified as a reference homozygote (genotype=0); if the base was the same as the mutant, it was classified as the mutant homozygote (genotype=2), otherwise if both alleles were present, it was called a heterozygote (genotype=1). For ASE testing, only those classified as heterozygotes (genotype $=1$ ) were analyzed further.

\section{Statistical Analysis}

The experimental design employed was a 2x2x2 factorial of Alcohol Drinking (AD) (water control vs. ethanol drinking initiated during adolescence), sex (male vs. female), and direction of the cross (i.e. parental origin) (HAD sire $x$ LAD dam vs. LAD sire x HAD dam). The sample size of each condition was 5 rats, for a total of 40 rats from the ten $\mathrm{F} 1$ litters. The results were analyzed as categorical data in two ways. In the first analysis, the main effect of treatment (coded as dummy variable 1 and -1 for each level of the factor) and their interactions (found as

This article is protected by copyright. All rights reserved. 
the product of main effect dummy variables) on ASE was examined. For each of the treatment comparisons, a 2x2 chi-square test of independence was employed. For this test, the cells were the number of counts of each SNP for that locus, the rows were the respective treatments, or interactions of these treatments, and columns were alternative SNPs. The test was adjusted for over-dispersion by estimating a scale parameter associated with the degree of variance inflation, as shown by (McCullagh and Nelder, 1989). Significance was determined by computing the false discovery rate (FDR), which was calculated according to Benjamini and Hoshberg (1995) (Benjamini and Hochberg, 1995).

In the second analysis, the effect of amount of alcohol consumed (Alcohol Drinking Level: $A D L)$ on ASE was examined. For that analysis only data from rats that had access to ethanol were used in a chi-square test for trend as shown by (Armitage et al., 2001). In this test, allelic proportions were regressed across $A D L$, and corrected for over-dispersion. Allelic proportion was calculated as the number of SNP reads of the non-reference allele over the total number of reads at that position. This analysis is equivalent to a linear regression of allelic proportions regressed on $A D L$ weighted by the observed total number of reads at that position. In addition, interactions of $A D L$ with sex and/or parental genotype were found by coding the independent variable for the regression as the product of the $A D L$ multiplied by the dummy variable for sex or parental origin.

\section{Manhattan Plots}

To give a global perspective of the genome-wide magnitude and spatial distribution of ASEs, we created a Manhattan plot based on the ' LL ' values on Chrs 1-20 and the X chromosome. "LL" is the negative of the log likelihood of the significance level (p) and was calculated using the formula given in Armitage et al., 2001(Armitage et al., 2001). The plot was generated using MATLAB 8.3 (The MathWorks, Inc., Natick, MA, USA).

This article is protected by copyright. All rights reserved. 


\section{RESULT}

The analyses revealed a significant number of differentially expressed ASE SNPs (Table 1) as a function of $A D$, and as a function of $A D L$. These are summarized in Table 1.

\section{Alcohol-Drinking (AD) Related ASE}

Two statistical factors, effect of $A D$ and effect of $A D L$, were used for the initial analysis of the ASEs in F1 HAD2/LAD2 progeny. Analysis of the first factor AD (Alcohol Drinking vs Water only) revealed 41,096 SNPs with differential allelic proportions at a FDR of $<0.05$ (see Table 1), 369 SNPs showed ASE (cis-acting regulatory factors) in 310 genes (FDR $<0.05)$ induced by $A D$. A number of these ASE genes were associated with proteins mediating biological functions including (1) alcohol metabolism (aldehyde dehydrogenase 2, Aldh2), (2) hormone receptor [nuclear receptor subfamily 3, group C, member 1, (Nr3c1), glucocorticoid receptor (GR)], (3) neurotransmitter receptor (cholecystokinin B receptor, Cckbr), (4) neurotransmitter transporter (e.g. glutamate transporter, Slc1a1), (5) synaptic function, (6) epigenetics, as well as (7) immune and (8) stress activity (see Table 2, Column A).

\section{Alcohol-Drinking Level (ADL) Related ASE}

Analysis of the second factor, $A D L$, see Method section, revealed a total of 41,099 ASE SNPs that were significantly (FDR<0.05) affected by $A D L$ (see Table 1), including 391 ASE SNPs with cis-regulation in 293 genes. Two examples of the $A D L$ associated changes of allelic proportion are demonstrated in Fig. 1.

This article is protected by copyright. All rights reserved. 
ASE genes influenced by $A D L$ also included functional categories of Hormone receptor-related, Neurotransmitter receptor, Neurotransmitter transporter, lon channel, Synaptic function, Epigenetics, Inflammation and Stress activity, as well as ATP-related and other biological functions (see Table 2 Column B). It is noteworthy that some of the genes overlapped between these two categories (Detailed below).

Comparison of the $A D-A S E$ and the $A D L-A S E$ findings revealed that there were 65 common genes (Fig. 2A). Of these 65 genes, 50 genes had the exact same ASE loci identified by the two analyzes (Fig. 2B). These genes included cholecystokinin B receptor (Cckbr); neuronal cell adhesion molecule (Nrcam); a critical transporter for glutamate/aspartate (SIc25a12), cation ion transporter (S/c24a2), as well as a monocarboxylic acid transporter (S/c16a14); thyroid hormone receptor interactor 12 (Trip12); and DEAD/H (Asp-Glu-Ala-Asp/His) box helicase 11 (Ddx11); among others. The differential distribution of the ASE genes, induced by $A D$ and $A D L$, across chromosomes are shown in the Manhattan plots of Figs. 3a and $\mathbf{3 b}$.

\section{Sex Effect on ASE}

In the F1 progeny, 8,480 ASE SNPs in 3,845 genes (FDR $<0.05)$, or 3,664 ASE SNPs in 2,075 genes $(F D R<0.001)$ were significantly different between the sexes. Among them, a number of gender-differential ASEs also were a function of $A D$. First, we found 316 ASE SNPs in 262 genes (FDR $<0.05)$ were differentially affected by $A D$ between the sexes ( $\mathbf{S} 2$ Table $\mathbf{A})$. Of these ASEs, 18 had regulatory significant SNPs (SS) including in promoter regions of the parental genome (e.g. St5, Snrk, Abhd16a, and Kcnf1). The second analysis revealed that 205 ASEs in 140 genes (FDR < 0.05) were differentially affected by $A D L$ between the sexes ( $\mathbf{S 2}$ Table B).

This article is protected by copyright. All rights reserved. 


\section{Parental -Origin Effect on ASE}

Regarding parental origin effects, 1890 SNPs in 1346 genes (FDR < 0.05) or 534 SNPs in 405 genes $(F D R<0.001)$ showed allelic imbalance due to parental origin (HAD sire $x$ LAD dam vs LAD sire $x$ HAD dam). $A D$ had a significant effect on parental-origin ASEs, such that 459 ASE SNPs in 349 genes (FDR < 0.05) were identified (S3 Table A). Of the $A D$ by parental-origin ASE SNPs, 20 were located in regulatory regions of the parent genes (e.g. Acaa1, Tango2, Pmepa1, Pmepa1, and Dock1). ADL also had a significant effect on parental-origin ASEs, such that 279 differential ASEs in 201 genes (FDR < 0.05) were identified (S3 Table B).

\section{DISCUSSION}

Classic Mendelian inheritance assumes that genes from each parental chromosome contribute equally to the phenotype. Nevertheless, X-chromosome and autosomal imprinting inactivation are the two better known exceptions to this assumption. ASE has been increasingly identified in human genetic studies. Analysis of human SNP chips of the liver, kidney, and fetuses have indicated that $\sim 600$ out of $\sim 1500$ analyzed SNPs showed at least a twofold difference in ASE (Lo et al., 2003). And many research questions warrant this type of investigation. This would allow one to determine the impact of ASEs and their transcriptional magnitude in delineating the role of genetics in AUDs. For instance, a compelling question is how do polymorphisms in regulatory regions, with differential ASEs, interact with environmental factors to promote or interfere with a susceptibility to develop AUDs. Importantly, the present study revealed that 9 weeks of alcohol drinking, an example of an environmental effect, altered ASE in a diverse array of genes. Moreover, some of these effects, of alcohol drinking, on ASE were sex-specific (S2 Table). Interestingly, reciprocal cross-breeding revealed that parental genotype also played a significant role in differential ASE (S3 Table).

This article is protected by copyright. All rights reserved. 


\section{ASE Gene Profiles}

Regarding the $A D$-ASE and ADL-ASE sets of identified genes, one out of every six ASE genes ( 65 of $\sim 300$ genes) was common between these two analyses. Of these common genes, $\sim 75 \%$ shared the same ASE location. These common genes included ones previously implicated in alcohol drinking behavior. These previously identified genes included cholecystokinin B receptor (Cckbr Cck2r), known to modulate dopamine activity in the striatum as well as gamma-aminobutyric acid (GABA) activity in the nucleus accumbens (NAc), with both of these functions critically important in reinforcement and reward behavior (Altar and Boyar, 1989, Lanza and Makovec, 2000). For instance, a Val125 variant has been associated with alcohol dependence in a Finnish population (Vanakoski et al., 2001) as well as cocaine sensitivity (Crespi, 1998). Similarly, another cholecystokinin A receptor subunit gene polymorphism, $-81 \mathrm{G}$ allele, has been associated with alcohol dependence in a Japanese population (Miyasaka et al., 2004). In addition, the Cck gene contains a significant SNP with differential expression between HAD and LAD rats (Lo et al., 2016). Glutamate (Glu) and GABA are key neurotransmitters mediating ethanol drinking behavior. Therefore, it is noteworthy that the Glu transporter gene, SIc25a12, is common in both the AD-ASE and ADL-ASE sets of identified genes. Similarly, another glutamate transporter gene, S/c1a1, was significantly altered by $A D$, and the GABA transporter gene, S/c6a7, was significantly altered by $A D L$ (Table 2).

Of equal importance was the observation of homologous genes with similar function in these gene sets, even though these genes may not have had the same name per se. This is exemplified by findings of significant ASE differences in ion channel genes including (a) potassium channels (Kcng4 was changed by $A D$, and Kcnc3, Kcnab2, Kcnf1 were altered by $A D L$ ), (b) sodium channels (Scn8a was changed by $A D$; while $A D L$ mediated Scn2a, Scn9a changes), and (c) calcium channels (Cacna1a and Cacna1g was changed by $A D$; while Cacnb1 was changed by $A D L$, see Table 2). These ion channels serve important functions in neuronal This article is protected by copyright. All rights reserved. 
function and transmission. Similarly, homologous genes were found in ATP-related genes (e.g., Atp2a2 and Atp2b2 were changed by AD; while Atp1a2, Atp2a2, Atp2b2, Atp2b3, Atp8a1 were change by $A D L$ ) as well. Regarding the ATPases, changes in Atp8a1 expression levels in the hippocampus have been associated with altered synaptic strength, electrical activity, and autistic-like behavior (Kerr et al., 2016). Therefore, it is noteworthy that the current findings indicate that cis-acting factors contributing to ASE (whether influenced by alcohol access or by alcohol drinking level) are not necessarily limited to a single transcriptome, but may also affect homologous transcriptomes in a respective functional category. These homologous transcriptomes may reflect gene families with alternative combinations of subunits, or isoforms in the proximal loci vicinity. We propose that this is an example of functional genetics, which is an area of study warranting further work.

The $A D$ - and $A D L$-induced effects on ASE of epigenetic-associated genes was another novel finding from this study (see Table 2). These epigenetic-related genes included histone methyltransferase activity (SetD2, SET domain containing 2 for histone 3; and Kmt2e, lysine-specific methyltransferase $2 \mathrm{E}$, which were altered by $A D$ ); histone deacetylation (Sirt2, sirtuin 2 was altered by $A D L$ ); and acetyl binding protein ( $\mathrm{Brd} 4$, bromodomain 4 which was altered by AD). Importantly, these epigenetic-related genes further regulate transcription, for example cap methyltransferase 1 (Cmtr1) increases levels of mRNA translation, a histone variant, H2afy, represses transcription, and DEAD/H box helicase 11 ( $D d x 11)$ regulates translation initiation, splicing, as well as ribosome and spliceosome assembly. These data not only indicate that alcohol affects the transcriptome of epigenetic-related genes, but also suggest that these epigenetic genes may subsequently affect the transcription of other genes. Other functional categories in the $A D$ - and $A D L$-affected ASE gene sets included synaptic neuroplasticity and adaptation, as well as genes associated with inflammation and stress activity with possible roles in alcohol-associated negative reinforcement (see Table 2).

This article is protected by copyright. All rights reserved. 


\section{Potential Mechanism of Alcohol on ASE}

An ASE gene is identified when one allele is differentially expressed over the other, which can only be attributed to a cis-acting regulatory factor. A trans-acting factor would not differentially affect which allele was expressed, but rather the extent to which both alleles were expressed. The present study was not designed to identify trans-acting factors. Therefore, our discussion will focus on cis-acting regulatory factors. A cis-acting regulatory factor can be directly impacted by an environmental stimulus or by another cis-acting factor further upstream in the regulatory process. Such upstream regulatory factors can, in turn, also be influenced by environmental stimuli, such as alcohol drinking. Furthermore, alleles can be silenced due to methylation in the gametes passed on by one parent or the other (i.e., imprinting).

The ASEs identified in the present study were likely due to a complex interaction between (a) genomic SNPs in the regulatory regions (promoter, enhancer, insulator and junctional region between intron and exon), (b) innate (inherited) differential epigenetics (e.g. imprinting as a result of DNA methylation), and/or (c) acquired epigenetics such as those, at least in part, induced by alcohol drinking. Regarding the first possibility, since the parental genome has been previously identified (Lo et al., 2016), we have identified 28 (14 from $A D$ and 14 from $A D L$ ) ASE genes that have regulatory SNPs, which may influence ASE transcription (S4 Table). Regarding the second (innate epigenetics: including inheritable imprinting) possibility, we found a few ASE genes [e.g. Sphingomyelin Phosphodiesterase 1 (Smpd1), nucleosome assembly protein 1-like 5 (Nap1/5)] meeting these criteria. This strongly suggests that many of the remaining ASEs were influenced by the third possibility, an environmental factor presumably alcohol, within the generation exposed to alcohol. Importantly, within the environmental factor of alcohol consumption (i.e., $A D)$, ASE was affected by $A D L$ as well. Overall, these findings support our contention that ASE is 
relatively common among non-imprinted autosomal genes. An important future direction will be to determine if the variant imbalances observed in the above functional categories can be transmitted across generations, which would add a third layer of inquiry to the gene-by-environment interactional effect on alcohol-drinking behavior.

\section{Gender and Parental Origins of ASE Effects}

The current study also revealed a significant effect of sex on ASE, such that $\sim 3500$ SNPs were associated with ASEs of roughly 2000 genes (FDR < 0.001). Alcohol also interacted significantly with this sex effect, although the mechanism for this interaction is unknown and needs further investigation. A number of these ASE genes have SNPs in regulatory regions i.e., in the promoter region of the parental gene (e.g. St5, Snrk, Itgb1bp1, Trappc9, Abhd16a, Kcnf1) (Lo et al., 2016). These parental SNPs may serve as cis-acting regulators. Thus, alcohol may affect the regulatory regions, which in turn affects sex-modulation of these ASE genes. For example, Kcnf1, a voltage gated potassium (Kv) channel regulates neurotransmitter release, neuronal excitability, heart rate, insulin secretion, and smooth muscle contraction; in addition, and importantly it is also a signature SNP between the HAD and LAD rat lines (Lo et al., 2016). Interestingly, there were five sex-modulated ASE sites associated with Trappc9, which encodes a protein that likely plays a role in NF-kappa-B signaling. Mutations in Trappc9 have been associated with autosomal-recessive mental retardation (Mir et al., 2009). In addition, Trappc9

has been implicated in ethanol-associated effects (Mulligan et al., 2006, Ponomarev et al., 2012). Another sex-affected gene, Abhd16a, is within the human major class III histocompatibility complex region and interacts with cyclooxygenase-2 (Cox-2) (Turcotte et al., 2017) as well as Abhd12 and associated with lipopolysaccharide (LPS)-induced cytokine production (Kamat et al.,

This article is protected by copyright. All rights reserved. 
2015). Regarding this, the Trappc9 and Abhd16a proteins as well as NF-kappa-B signaling are commonly associated with neuroinflammation (Kim, 2015).

The present study also found that a paternal versus maternal predisposition for excessive alcohol drinking (i.e., a HAD rat) was a significant determinant of about 700 ASE genes (in the combined set of $A D$ - and $A D L$-associated genes). Thus, paternal versus maternal alcoholics may differentially affect transcription through ASE genes. Importantly, this parallels findings from human studies (Morgan et al., 2010, Coffelt et al., 2006) suggesting parental sex-related influences on phenotypic (e.g. psychiatric disorders) expression. Overall, these findings (e.g. common loci, genes, and functional categories between the AD-ASE and the ADL-ASE gene sets) suggest that alcohol-induced ASEs are significantly affected by a paternal vs maternal genetic predisposition to develop AUDs and this has the potential to alter subsequent transcriptional activity.

The cause of differential effect of paternal or maternal origin is unclear. DNA methylation may be attributed to parental origin since the F1s of either line share the same genetic information at those loci, irregardless of parental origin. Thus, the allelic expression difference in the reciprocal crossed F1s is a very interesting but more complex phenomenon than it first appears. Besides differential imprinting (inherited methylation) between maternal and paternal loci, there is also evidence that the C/G SNPs between parents, in promoter regions, can also influence methylation patterns in adjacent regions.

\section{Summary}

Although ASEs are widespread across the genome (Palacios et al., 2009), alcohol's influence on allele-specific expression has not been systematically investigated. A recent report indicated prenatal alcohol exposure altered maternal ASE of lodothyronine Deiodinase 3 (Dio3) This article is protected by copyright. All rights reserved. 
and insulin-like growth factor 2 (lgf2) genes (Tunc-Ozcan et al., 2017). Also, a human study investigating the association between alcohol dependence and the gamma 3 GABA receptor subunit, GABRG3 revealed multiple SNPs in the GABRG3 gene (Dick et al., 2004). The SNPs in GABRG3 may be in the cis-acting regulatory factors that influence ASE, but this will require further investigation. The present finding of an imbalance in parental allele expression suggests that there is a high level of cis-acting regulation within this animal model of alcoholism. In addition, the present ASE findings indicated that there are significant contributions from the genetic variants observed between the HAD vs LAD animal model of genetic predisposition (Lo et al., 2016) that can be associated with alcohol drinking behaviors (Bell et al., 2017, McBride et al., 2014). Furthermore, the present study showed alcohol-drinking, including level of intake, influenced ASE. This supports the hypothesis that a gene-by-environment interaction mediates, at least in part, AUDs; and, in fact, suggests a third dimension of influence that could be depicted as an environment-by-gene-by-environment interaction. Both sex-of-progeny and parental genotype/phenotype (i.e. HAD vs LAD) affected ASE, and this effect also interacted with the effects of alcohol drinking ( $A D$ and $A D L)$. In summary, the causes of the observed differences in ASE will require further research, but the present findings suggest that (1) parental genomic structure, (2) inheritable allelic specific expression, (3) sex-of-progeny, and (4) epigenetic alterations induced by alcohol drinking are major potential factors influencing a predisposition for, and/or the development of, AUDs. Our sequencing of the parental genome provides the addiction field of research with important opportunities to determine whether epigenetic changes have occurred in the cis-acting elements of these identified ASE genes.

This article is protected by copyright. All rights reserved. 


\section{ACKNOWLEDGEMENT}

The study is supported by P60 AA07611 (FCZ and WMM), NIH AA016698 (FCZ), and AA013522 (RLB). The authors would like to thank Jill Reiter and Tammy Grave for assisting in RNA extraction.

\section{References}

ALTAR, C. A. \& BOYAR, W. C. 1989. Brain CCK-B receptors mediate the suppression of dopamine release by cholecystokinin. Brain Res, 483, 321-6.

ARMITAGE, P., BERRY, G. \& MATTHEWS, J. N. S. 2001. Statistical methods in medical research, Malden, MA, Blackwell Science.

BELL, R. L., HAUSER, S. R., LIANG, T., SARI, Y., MALDONADO-DEVINCCI, A. \& RODD, Z. A. 2017. Rat animal models for screening medications to treat alcohol use disorders. Neuropharmacology, 122, 201-243.

BELL, R. L., SABLE, H. J., COLOMBO, G., HYYTIA, P., RODD, Z. A. \& LUMENG, L. 2012. Animal models for medications development targeting alcohol abuse using selectively bred rat lines: neurobiological and pharmacological validity. Pharmacol Biochem Behav, 103, 119-55.

BENJAMINI, Y. \& HOCHBERG, Y. 1995. Controlling the False Discovery Rate: A Practical and Powerful Approach to Multiple Testing. Journal of the Royal Statistical Society. Series B (Methodological), $57,289-300$.

This article is protected by copyright. All rights reserved. 
COFFELT, N. L., FOREHAND, R., OLSON, A. L., JONES, D. J., GAFFNEY, C. A. \& ZENS, M. S. 2006. A longitudinal examination of the link between parent alcohol problems and youth drinking: the moderating roles of parent and child gender. Addict Behav, 31, 593-605.

COWLES, C. R., HIRSCHHORN, J. N., ALTSHULER, D. \& LANDER, E. S. 2002. Detection of regulatory variation in mouse genes. Nat Genet, 32, 432-7.

CRESPI, F. 1998. The role of cholecystokinin (CCK), CCK-A or CCK-B receptor antagonists in the spontaneous preference for drugs of abuse (alcohol or cocaine) in naive rats. Methods Find Exp Clin Pharmacol, 20, 679-97.

DI CHIARA, G. \& IMPERATO, A. 1988. Drugs abused by humans preferentially increase synaptic dopamine concentrations in the mesolimbic system of freely moving rats. Proc Natl Acad Sci U S A, 85, 5274-8.

DICK, D. M., EDENBERG, H. J., XUEI, X., GOATE, A., KUPERMAN, S., SCHUCKIT, M., CROWE, R., SMITH, T. L., PORJESZ, B., BEGLEITER, H. \& FOROUD, T. 2004. Association of GABRG3 with alcohol dependence. Alcohol Clin Exp Res, 28, 4-9.

EDENBERG, H. J., DICK, D. M., XUEI, X., TIAN, H., ALMASY, L., BAUER, L. O., CROWE, R. R., GOATE, A., HESSELBROCK, V., JONES, K., KWON, J., LI, T. K., NURNBERGER, J. I., JR., O'CONNOR, S. J., REICH, T., RICE, J., SCHUCKIT, M. A., PORJESZ, B., FOROUD, T. \& BEGLEITER, H. 2004. Variations in GABRA2, encoding the alpha 2 subunit of the $G A B A(A)$ receptor, are associated with alcohol dependence and with brain oscillations. Am J Hum Genet, 74, 705-14.

HANSEN, C. \& SPUHLER, K. 1984. Development of the National Institutes of Health genetically heterogeneous rat stock. Alcoholism, clinical and experimental research, 8, 477-9.

This article is protected by copyright. All rights reserved. 
HUANG, W. C., FERRIS, E., CHENG, T., HORNDLI, C. S., GLEASON, K., TAMMINGA, C., WAGNER, J. D., BOUCHER, K. M., CHRISTIAN, J. L. \& GREGG, C. 2017. Diverse Non-genetic, Allele-Specific Expression Effects Shape Genetic Architecture at the Cellular Level in the Mammalian Brain. Neuron, 93, 1094-1109 e7.

KAMAT, S. S., CAMARA, K., PARSONS, W. H., CHEN, D. H., DIX, M. M., BIRD, T. D., HOWELL, A. R. \& CRAVATT, B. F. 2015. Immunomodulatory lysophosphatidylserines are regulated by ABHD16A and ABHD12 interplay. Nat Chem Biol, 11, 164-71.

KERR, D. J., MARSILLO, A., GUARIGLIA, S. R., BUDYLIN, T., SADEK, R., MENKES, S., CHAUHAN, A., WEN, G. Y., MCCLOSKEY, D. P., WIERASZKO, A. \& BANERJEE, P. 2016. Aberrant hippocampal Atp8a1 levels are associated with altered synaptic strength, electrical activity, and autistic-like behavior. Biochim Biophys Acta, 1862, 1755-65.

KIM, H. Y. 2015. Phospholipids: a neuroinflammation emerging target. Nat Chem Biol, 11, 99-100.

LANZA, M. \& MAKOVEC, F. 2000. Cholecystokinin (CCK) increases GABA release in the rat anterior nucleus accumbens via CCK(B) receptors located on glutamatergic interneurons. Naunyn Schmiedebergs Arch Pharmacol, 361, 33-8.

LI, T. K. \& LUMENG, L. 1984. Alcohol preference and voluntary alcohol intakes of inbred rat strains and the National Institutes of Health heterogeneous stock of rats. Alcohol Clin Exp Res, 8, 485-6.

LO, C. L., LOSSIE, A. C., LIANG, T., LIU, Y., XUEI, X., LUMENG, L., ZHOU, F. C. \& MUIR, W. M. 2016. High Resolution Genomic Scans Reveal Genetic Architecture Controlling Alcohol Preference in Bidirectionally Selected Rat Model. PLoS Genet, 12, e1006178.

LO, H. S., WANG, Z., HU, Y., YANG, H. H., GERE, S., BUETOW, K. H. \& LEE, M. P. 2003. Allelic variation in gene expression is common in the human genome. Genome Res, 13, 1855-62.

This article is protected by copyright. All rights reserved. 
MANOLIO, T. A., COLLINS, F. S., COX, N. J., GOLDSTEIN, D. B., HINDORFF, L. A., HUNTER, D. J., MCCARTHY, M. I., RAMOS, E. M., CARDON, L. R., CHAKRAVARTI, A., CHO, J. H., GUTTMACHER, A. E., KONG, A., KRUGLYAK, L., MARDIS, E., ROTIMI, C. N., SLATKIN, M., VALLE, D., WHITTEMORE, A. S., BOEHNKE, M., CLARK, A. G., EICHLER, E. E., GIBSON, G., HAINES, J. L., MACKAY, T. F., MCCARROLL, S. A. \& VISSCHER, P. M. 2009. Finding the missing heritability of complex diseases. Nature, 461, 747-53.

MCBRIDE, W. J. \& LI, T. K. 1998. Animal models of alcoholism: neurobiology of high alcohol-drinking behavior in rodents. Crit Rev Neurobiol, 12, 339-69.

MCBRIDE, W. J., RODD, Z. A., BELL, R. L., LUMENG, L. \& LI, T. K. 2014. The alcohol-preferring (P) and high-alcohol-drinking (HAD) rats--animal models of alcoholism. Alcohol, 48, 209-15.

MCCULLAGH, P. \& NELDER, J. A. 1989. Generalized linear models, London ; New York, Chapman and Hall.

MIR, A., KAUFMAN, L., NOOR, A., MOTAZACKER, M. M., JAMIL, T., AZAM, M., KAHRIZI, K., RAFIQ, M. A., WEKSBERG, R., NASR, T., NAEEM, F., TZSCHACH, A., KUSS, A. W., ISHAK, G. E., DOHERTY, D., ROPERS, H. H., BARKOVICH, A. J., NAJMABADI, H., AYUB, M. \& VINCENT, J. B. 2009. Identification of mutations in TRAPPC9, which encodes the NIK- and IKK-beta-binding protein, in nonsyndromic autosomal-recessive mental retardation. Am J Hum Genet, 85, 909-15.

MIYASAKA, K., YOSHIDA, Y., MATSUSHITA, S., HIGUCHI, S., MARUYAMA, K., NIINO, N., ANDO, F., SHIMOKATA, H., OHTA, S. \& FUNAKOSHI, A. 2004. Association of cholecystokinin-A receptor gene polymorphism with alcohol dependence in a Japanese population. Alcohol Alcohol, 39, 25-8.

This article is protected by copyright. All rights reserved. 
MORGAN, P. T., DESAI, R. A. \& POTENZA, M. N. 2010. Gender-related influences of parental alcoholism on the prevalence of psychiatric illnesses: analysis of the National Epidemiologic Survey on Alcohol and Related Conditions. Alcohol Clin Exp Res, 34, 1759-67.

MOYERBRAILEAN, G. A., RICHARDS, A. L., KURTZ, D., KALITA, C. A., DAVIS, G. O., HARVEY, C. T., ALAZIZI, A., WATZA, D., SOROKIN, Y., HAUFF, N., ZHOU, X., WEN, X., PIQUE-REGI, R. \& LUCA, F. 2016. High-throughput allele-specific expression across 250 environmental conditions. Genome Res, $26,1627-1638$.

MULLIGAN, M. K., PONOMAREV, I., HITZEMANN, R. J., BELKNAP, J. K., TABAKOFF, B., HARRIS, R. A., CRABBE, J. C., BLEDNOV, Y. A., GRAHAME, N. J., PHILLIPS, T. J., FINN, D. A., HOFFMAN, P. L., IYER, V. R., KOOB, G. F. \& BERGESON, S. E. 2006. Toward understanding the genetics of alcohol drinking through transcriptome meta-analysis. Proc Natl Acad Sci U S A, 103, 6368-73.

MURPHY, J. M., STEWART, R. B., BELL, R. L., BADIA-ELDER, N. E., CARR, L. G., MCBRIDE, W. J., LUMENG, L. \& LI, T. K. 2002. Phenotypic and genotypic characterization of the Indiana University rat lines selectively bred for high and low alcohol preference. Behav Genet, 32, 363-88.

OLSEN, C. M. 2011. Natural rewards, neuroplasticity, and non-drug addictions. Neuropharmacology, 61, 1109-22.

PALACIOS, R., GAZAVE, E., GONI, J., PIEDRAFITA, G., FERNANDO, O., NAVARRO, A. \& VILLOSLADA, P. 2009. Allele-specific gene expression is widespread across the genome and biological processes. PLoS One, 4, e4150.

PONOMAREV, I., WANG, S., ZHANG, L., HARRIS, R. A. \& MAYFIELD, R. D. 2012. Gene coexpression networks in human brain identify epigenetic modifications in alcohol dependence. J Neurosci, $32,1884-97$.

This article is protected by copyright. All rights reserved. 
SANDER, T., BALL, D., MURRAY, R., PATEL, J., SAMOCHOWIEC, J., WINTERER, G., ROMMELSPACHER, H., SCHMIDT, L. G. \& LOH, E. W. 1999. Association analysis of sequence variants of GABA(A) alpha6, beta2, and gamma2 gene cluster and alcohol dependence. Alcohol Clin Exp Res, 23, 427-31.

TREUTLEIN, J., CICHON, S., RIDINGER, M., WODARZ, N., SOYKA, M., ZILL, P., MAIER, W., MOESSNER, R., GAEBEL, W., DAHMEN, N., FEHR, C., SCHERBAUM, N., STEFFENS, M., LUDWIG, K. U., FRANK, J., WICHMANN, H. E., SCHREIBER, S., DRAGANO, N., SOMMER, W. H., LEONARDI-ESSMANN, F., LOURDUSAMY, A., GEBICKE-HAERTER, P., WIENKER, T. F., SULLIVAN, P. F., NOTHEN, M. M., KIEFER, F., SPANAGEL, R., MANN, K. \& RIETSCHEL, M. 2009. Genome-wide association study of alcohol dependence. Arch Gen Psychiatry, 66, 773-84.

TUNC-OZCAN, E., WERT, S. L., LIM, P. H., FERREIRA, A. \& REDEI, E. E. 2017. Hippocampus-dependent memory and allele-specific gene expression in adult offspring of alcohol-consuming dams after neonatal treatment with thyroxin or metformin. Mol Psychiatry.

TURCOTTE, C., ZARINI, S., JEAN, S., MARTIN, C., MURPHY, R. C., MARSOLAIS, D., LAVIOLETTE, M., BLANCHET, M. R. \& FLAMAND, N. 2017. The Endocannabinoid Metabolite Prostaglandin E2 (PGE2)-Glycerol Inhibits Human Neutrophil Functions: Involvement of Its Hydrolysis into PGE2 and EP Receptors. J Immunol, 198, 3255-3263.

VAN BEEK, J. H., WILLEMSEN, G., DE MOOR, M. H., HOTTENGA, J. J. \& BOOMSMA, D. I. 2010. Associations between ADH gene variants and alcohol phenotypes in Dutch adults. Twin Res Hum Genet, 13, 30-42.

VANAKOSKI, J., VIRKKUNEN, M., NAUKKARINEN, H. \& GOLDMAN, D. 2001. No association of CCK and CCK(B) receptor polymorphisms with alcohol dependence. Psychiatry Res, 102, 1-7.

This article is protected by copyright. All rights reserved. 
WARD, L. D. \& KELLIS, M. 2012. Interpreting noncoding genetic variation in complex traits and human disease. Nat Biotechnol, 30, 1095-106.

YAN, H., YUAN, W., VELCULESCU, V. E., VOGELSTEIN, B. \& KINZLER, K. W. 2002. Allelic variation in human gene expression. Science, 297, 1143.

ZHANG, F. \& LUPSKI, J. R. 2015. Non-coding genetic variants in human disease. Hum Mol Genet, 24, R102-10.

ZHOU, Z., KARLSSON, C., LIANG, T., XIONG, W., KIMURA, M., TAPOCIK, J. D., YUAN, Q., BARBIER, E., FENG, A., FLANIGAN, M., AUGIER, E., ENOCH, M. A., HODGKINSON, C. A., SHEN, P. H., LOVINGER, D. M., EDENBERG, H. J., HEILIG, M. \& GOLDMAN, D. 2013. Loss of metabotropic glutamate receptor 2 escalates alcohol consumption. Proc Natl Acad Sci U S A, 110, 16963-8.

Figure Legends

Fig. 1. Examples of the Alcohol Drinking Level (ADL) associated with changes of allelic proportion. (A) Example of allelic imbalance in the Sorting nexin 17 (Snx17) gene (Chr6:26543926). The reference allele of this SNP is C, while the alternative allele is T, and changing in the DNA sequence results in missense mutation from Glycine (GGA) to Arginine (AGA) at the 168 protein position. Additionally, this SNP is at a splice donor site, which could affect alternative splicing. (B) Second example of ASE in the SPHK1-interactor, AKAP domain containing (Sphkap) at chr9: 89072920. This SNP is a missense variant, which changes from Glycine (GGG) to Valine (GTG) at the 765 protein position. Allelic proportion was calculated as

This article is protected by copyright. All rights reserved. 
the number of SNP reads of the non-reference allele over the total number of reads at that position.

Fig. 2. Comparison of $A D-A S E$ and $A D L-A S E$ genes. (A) Venn diagram shows the number of genes containing significant ASE at FDR 5\%. There are $~ 27 \%$ common (65) genes between $A D-A S E$ (246 genes) and the $A D L-A S E$ (228 genes). (B) Venn diagram showing the number of significant ASE by positions at FDR 5\%. There are 316 and 338 unique ASEs in $A D$ and $A D L$ respectively, and 53 ASEs (in 50 genes with same loci) shared between the two (about 1 out of 6). Combined, Figure 2 shows that among the 65 genes common to $A D$ and $A D L, 50$ of these genes have the same ASE loci.

Fig. 3. Distribution of ASE SNPs throughout chromosomes. (A) The distribution of $A D-A S E$ SNPs: the effect of Alcohol Drinking was plotted based on the "LL" value along chromosomes 1 to 20 and $X$. The red line at 3.355 indicating the cutoff for significance at FDR<0.05. "LL" is the negative of the log likelihood of the significance level $(p)$ and was calculated using the formula given in (Armitage et al., 2001).

(B) The distribution of ADL-ASE SNPs plotted as of Alcohol Drinking Level. The red line at 3.324 indicating the cutoff for significance at FDR<0.05.

This article is protected by copyright. All rights reserved. 
Table 1. ASE Exon SNPs as function of alcohol

\begin{tabular}{|l|c|c|c|}
\hline & Total SNPs & $\begin{array}{l}\text { Significant signature } \\
\text { at FDR 5\% }\end{array}$ & \# of genes \\
\hline ASE: As effect of AD & 41,096 & 369 & 310 \\
\hline ASE: As effect of ADL & 41,099 & 391 & 293 \\
\hline
\end{tabular}

This article is protected by copyright. All rights reserved. 
Table 2. Summary of Alcohol-Related ASE Genes.

\begin{tabular}{|c|c|c|}
\hline Biological functions & By Alcohol Drinking (AD) & By Alcohol Drinking Level (ADL) \\
\hline $\begin{array}{l}\text { Acetaldehyde } \\
\text { Metabolism }\end{array}$ & Aldh2 (aldehyde dehydrogenase 2) & \\
\hline Hormone Receptor & $\operatorname{Nr3c1}$ (GR, glucocorticoid receptor) & Trip12, Thrb (thyroid hormone receptor) \\
\hline $\begin{array}{l}\text { Neurotransmitter } \\
\text { Receptor }\end{array}$ & Cckbr (cholecystokinin B receptor) & $\begin{array}{l}\text { Cckbr (cholecystokinin B receptor) } \\
\text { Chrm1 (muscarinic cholinergic receptor), } \\
\text { Sstr3 (somatostatin receptor) }\end{array}$ \\
\hline $\begin{array}{l}\text { Neurotransmitter } \\
\text { Transporter }\end{array}$ & $\begin{array}{l}\text { Slc25a12 (glutamate/aspartate transporter), } \\
\text { Slc1a1 (glutamate transporter) }\end{array}$ & SIc25a12, Slc6a7 (GABA transporter) \\
\hline Ion Channel & $\begin{array}{l}\text { Kcnc3, Kcnab2, Kcnf1 (potassium channel); } \\
\text { Scn2a, Scn9a (sodium channel); Cacna1a, } \\
\text { Cacna1g (calcium channel) }\end{array}$ & $\begin{array}{l}\text { Kcng4 (potassium channel), Scn8a (sodium } \\
\text { channel), Cacnb1 (calcium channel) }\end{array}$ \\
\hline Epigenetics & $\begin{array}{l}\text { SetD2 (SET domain containing 2), Brd4 } \\
\text { (bromodomain), Kmt2e (lysine-specific } \\
\text { methyltransferase 2E); Ddx11 (DEAD/H box } \\
\text { helicase 11), H2afy (H2A histone variant) }\end{array}$ & $\begin{array}{l}\text { Sirt2 (sirtuin 2), Cmtr1 (cap } \\
\text { methyltransferase 1) }\end{array}$ \\
\hline $\begin{array}{l}\text { Inflammatory or Stress } \\
\text { Activity }\end{array}$ & $\begin{array}{l}\text { Hsbp1 (heat shock binding protein), Hspa12a } \\
\text { (heat shock protein), Irak3, I/34 (interleukin) }\end{array}$ & $\begin{array}{l}\text { Atg12 (autophagy related 12), Cd84, } \\
\text { Cyp2j10, (cytochrome P450), Coa5 } \\
\text { (cytochrome) }\end{array}$ \\
\hline Synaptic Function & $\begin{array}{l}\text { Camsap2 (calmodulin-regulated } \\
\text { spectrin-associated protein 2), Unc13a (unc-13 } \\
\text { homolog A), Sntb1 (syntrophin; beta 1) }\end{array}$ & $\begin{array}{l}\text { Rims1(regulating synaptic membrane } \\
\text { exocytosis 1), Syngr3 (synaptogyrin 3), } \\
\text { Nfasc (neurofascin) }\end{array}$ \\
\hline ATP-Related & $\begin{array}{l}\text { Atp1a4 (ATPase; } \mathrm{Na}+\mathrm{K}+\text { transporting), } \\
\text { Atp2a2, Atp2b2 (ATPase; Ca++ transporting), }\end{array}$ & $\begin{array}{l}\text { Atp1a2 (ATPase; } \mathrm{Na}+/ \mathrm{K}+\text { transporting), } \\
\text { Atp2a2, Atp2b2, Atp2b3 (ATPase; Ca++ }\end{array}$ \\
\hline
\end{tabular}

This article is protected by copyright. All rights reserved. 


\begin{tabular}{|l|l|l|}
\hline & Atpaf1 (ATP synthase assembly factor) & $\begin{array}{l}\text { transporting), Atp8a1 (ATPase), Abcg3/3 } \\
\text { (ATP-binding cassette) }\end{array}$ \\
\hline
\end{tabular}

\section{Table Legends}

Table 1. The number of significant signature and genes revealed as a function of Alcohol Drinking (AD) and Alcohol Drinking Level (ADL).

Table 2. Examples of alcohol-related ASE genes identified by Alcohol Drinking (AD), and Alcohol Drinking Level (ADL). These genes were categorized by biological functions (column1).

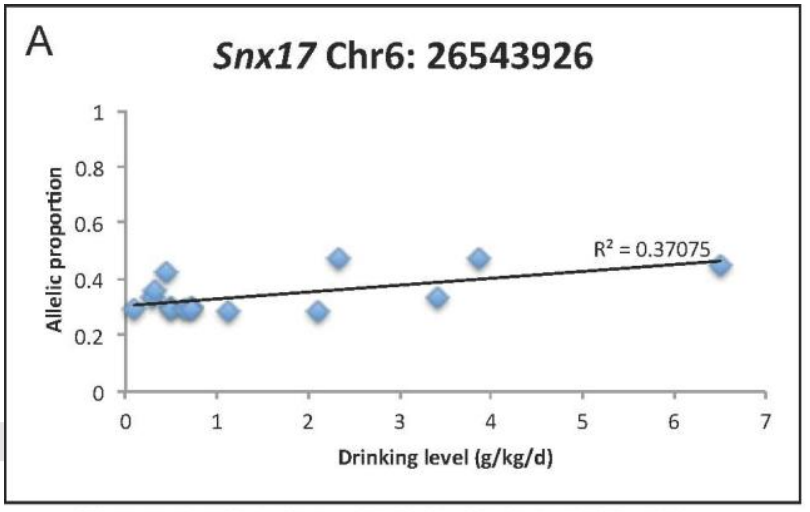

Missense splice donor, Ref: C, Alt: T (not CG site)

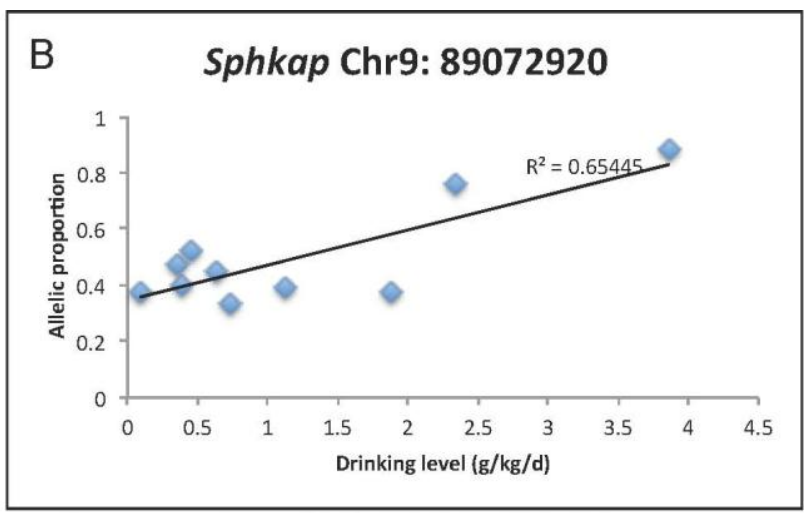

Missense variant, Ref: G, Alt: T (not CG site)

This article is protected by copyright. All rights reserved. 
A Number of Genes containing ASE

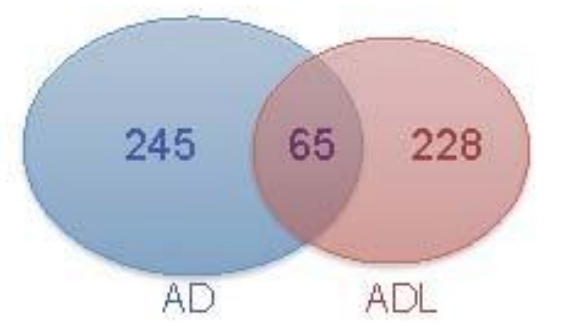

B Number of ASE (positions)

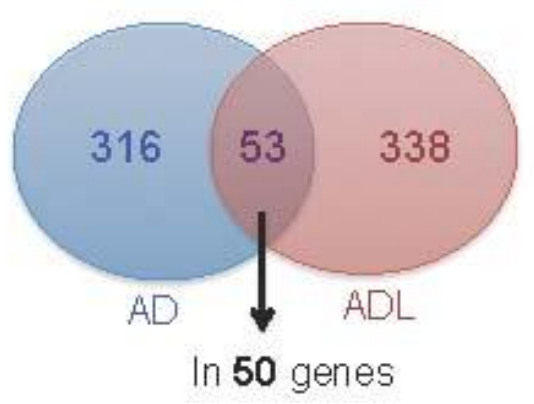

This article is protected by copyright. All rights reserved. 

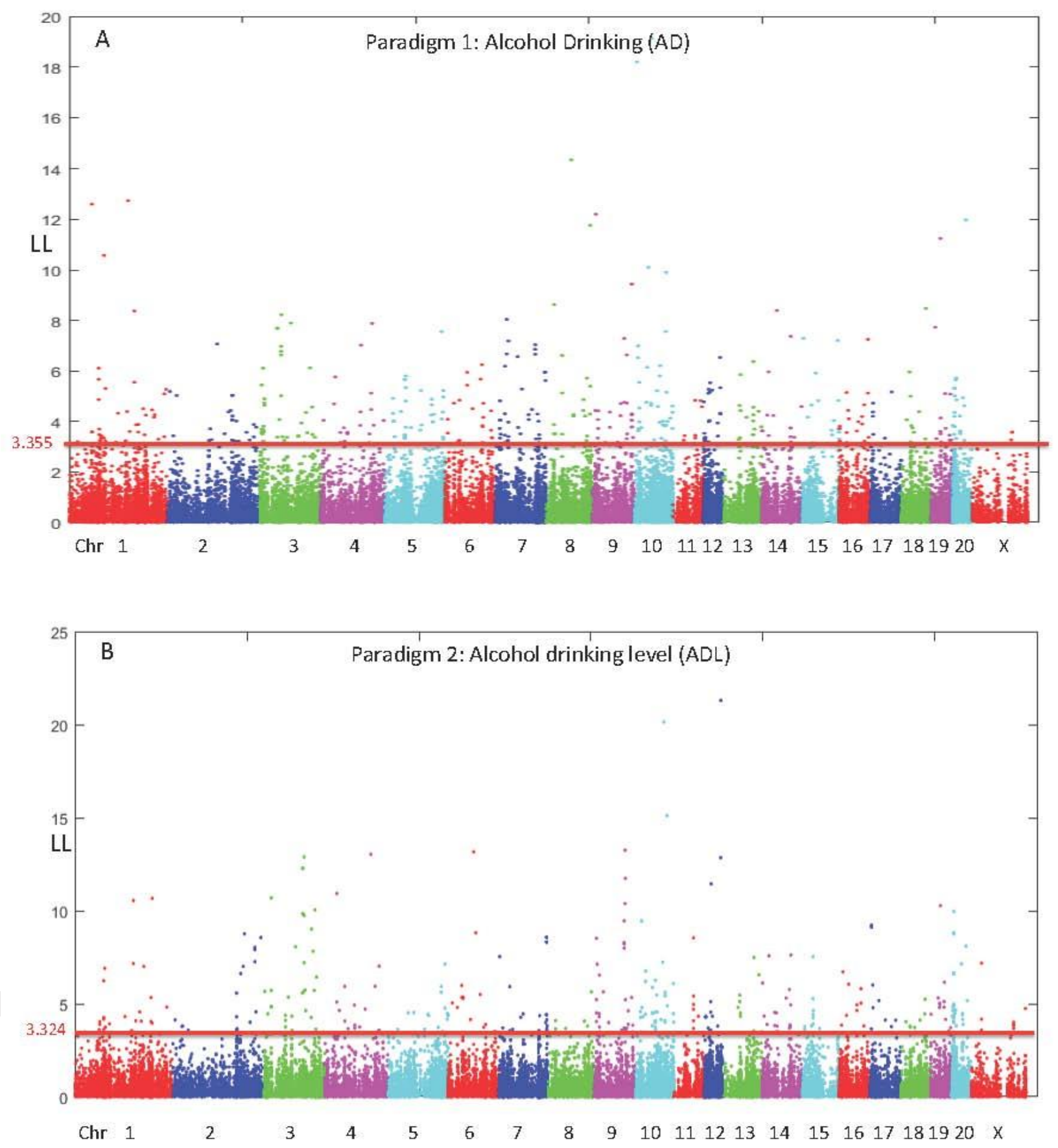

This article is protected by copyright. All rights reserved. 